\title{
CLÍNICA PSICODINÂMICA DO TRABALHO: A PRÁTICA EM DIVERSOS CONTEXTOS DE TRABALHO
}

\author{
PSYCHODYNAMIC CLINIC OF LABOUR: PRACTICE UNDER VARIOUS \\ WORK CONTEXTS
}

Liliam Deisy Ghizoni

Universidade Federal do Tocantins - UFT

Solene Nobre de Medeiros

Detran - DF

\begin{abstract}
Gerusa Menezes de Carvalho, Rosângela Dutra de Moraes e Priscila Moreira Santana Universidade Federal do Amazonas
\end{abstract}

Cláudia de Negreiros Magnus e Álvaro Roberto Crespo Merlo

Universidade Federal do Rio Grande do Sul

Perla Alves Martins Lima

Universidade Estadual de Roraima

Ana Magnólia Mendes

Universidade de Brasília

\begin{abstract}
RESUMO
O objetivo deste estudo é apresentar práticas clínicas, em diversos contextos de trabalho, realizadas recentemente de norte a sul do Brasil. A clínica psicodinâmica do trabalho caracteriza-se pela análise dos processos psíquicos mobilizados pelo encontro entre o sujeito e as imposições geradas pela organização do trabalho. São apresentadas cinco práticas clínicas desenvolvidas nos Laboratórios de Psicodinâmica do Trabalho da Universidade de Brasília e da Universidade Federal do Amazonas da Universidade Federal do Rio Grande do Sul. São práticas que sistematizam a metodologia em clínica do trabalho, apresentando especificidades e singularidades, a depender da realidade sociocultural e institucional de cada categoria estudada. As experiências relatadas evidenciam a diversidade de demandas e a importância da escuta clínica do sofrimento no trabalho. Os relatos evidenciam que a distância entre o prescrito e o real, que desencadeia o sofrimento, também está presente no fazer dos pesquisadores, demandando mobilização e criação de alternativas adequadas a cada realidade. Ainda, indica como perspectiva para futuros estudos, a necessidade de articular outros campos que contribuam para aprofundar o uso dos dispositivos de escuta. Apresenta-se como um referencial potente para essa referência a psicanálise. Essa articulação contribui para uma escuta analítica do sofrimento e sustenta uma proposta de construção de uma Clínica Analítica do Trabalho.
\end{abstract}

Palavras-chave: Clínica do trabalho; psicodinâmica do trabalho; espaço de discussão

ABSTRACT 
This study aims to present clinical practice under various work contexts, recently held from North to South of Brazil. The psychodynamic clinic of labour is characterized by the analysis of mental processes mobilized by the meeting between the subject and the impositions generated by the work organization five clinical practices are presented that are developed in laboratories of labor psychodynamics at the University of Brasilia (DF), Federal University of Amazonas and Federal University of Rio Grande do Sul, Brazil. These practices provide a systematic methodology in labour clinic resulting in unique practices depending on the sociocultural and institutional reality of each studied category. The reported experiences show the demand diversity and the importance of the clinic listening of work suffering. The reports show that the distance between the prescribed and the true rules which triggers the suffering is also the researchers' tasks, requiring mobilization and creation of suitable alternatives in each reality. It also indicates the need for future studies to articulate other fields that contribute to deepen the use of listening devices. It seems a powerful reference for psychoanalysis. This articulation contributes to suffering's analytical listening and supports a construction proposal of an Analytical Clinic of Labour.

Keywords: Labour Clinic; labour psychodynamics; discussion space

Recebido em 26/09/2015. Aceito em 18/11/2014. Publicado em 14/01/2015.

\section{INTRODUÇÃO}

As Clínicas do Trabalho formam um conjunto de abordagens teórico-metodológicas que têm como foco de estudo a relação entre trabalho e subjetividade. Em sua diversidade epistemológica, teórica e metodológica, as Clínicas do Trabalho têm um objeto comum: a situação de trabalho, com sujeito de um lado e trabalho e ambiente do outro (Bendassoli e Soboll, 2011).

Para esses autores, as Clínicas do Trabalho se aproximam de uma clínica social, uma vez que têm a realidade vivenciada pelos sujeitos como foco de pesquisa e intervenção, contemplando as vivências de sofrimento ancoradas nas experiências objetivas e subjetivas do trabalho. Porém, não devem ser confundidas com a clínica do sujeito, cuja ênfase está nos conflitos individuais.

Dentre as teorias que enfocam a subjetividade no trabalho, quatro abordagens clínicas estão sistematizadas: a Psicodinâmica do Trabalho, a Clínica da Atividade, a Psicossociologia e a Ergologia (Bendassoli e Soboll, 2011). O foco aqui será na Clínica Psicodinâmica do Trabalho, que é um modo de desvelar as mediações que ocorrem entre o sujeito e o real do trabalho. A tradução deste real se dá pela escuta do "clínico" sobre a fala do trabalhador e, deste modo, pode-se dar visibilidade às situações de trabalho, às vivências dos trabalhadores 
no seu cotidiano. Por ser uma clínica, a palavra, enquanto linguagem e forma de comunicação, é essencial para que o trabalho seja entendido, percebido e ressignificado pelo sujeito (Mendes e Araujo, 2012).

A abordagem da Psicodinâmica do Trabalho foi desenvolvida por Christophe Dejours, na França, a partir dos anos 80. A publicação de seu livro "A loucura do trabalho", em 1987, foi um marco para que a Psicodinâmica do Trabalho ganhasse espaço no Brasil. A Universidade de Brasília - UnB desponta com as primeiras pesquisas ancoradas nesse aporte teórico-metodológico nos anos 90, tendo a primeira dissertação de mestrado defendida em 1994, seguida da primeira tese de doutorado em 1999.

As relações dinâmicas entre a organização do trabalho e os processos de subjetivação - modos de pensar, sentir e agir dos trabalhadores, tanto individualmente quanto coletivamente - são os objetos de estudo dessa abordagem. Além disso, busca-se compreender como esse vínculo com o trabalho se manifesta nas vivências de prazer e sofrimento, nas estratégias de ação para mediar as contradições encontradas na organização do trabalho, nas patologias sociais, na saúde e no adoecimento. Trata-se, portanto, de uma abordagem que estuda as relações entre saúde mental e trabalho, assim como de uma metodologia que une pesquisa e intervenção. Caracteriza-se ainda pela análise dos processos psíquicos mobilizados pelo encontro entre o sujeito e a organização do trabalho (Mendes, 2007; Molinier, 2008).

A Psicodinâmica do Trabalho constitui aporte teórico para pesquisas, mas pode também ser uma ação, uma prática, uma Clínica Psicodinâmica do Trabalho, denominada por Dejours, no início dos anos 1990, como Clínica do Trabalho e da Ação. Os primeiros escritos desta Clínica chegaram ao Brasil, em 2004, na publicação de Lancman e Sznelwar.

Busca-se, com a Clínica Psicodinâmica do Trabalho, identificar as estratégias de mobilização subjetiva, que se caracterizam pelos modos de pensar, sentir e agir individual e coletivo dos trabalhadores e se fundamentam na inteligência prática, na cooperação e no espaço público de discussão (Dejours, 2012). Tem como função emancipar o sujeito, ressignificar o sofrimento e transformar a organização do trabalho em fonte de prazer e de saúde (Dejours e Molinier, 2011; Mendes e Araujo, 2012).

Destaca-se que existem diferenças estruturais entre o mundo do trabalho da França, berço da Psicodinâmica do Trabalho, e do Brasil, onde essa abordagem tem grande repercussão. Atualmente, os Laboratórios de Psicodinâmica do Trabalho da Universidade de Brasília, da Universidade Federal do Rio Grande do Sul e da Universidade Federal do 
Amazonas têm desenvolvido estudos sistematizados e contínuos com essa abordagem (Martins et al., 2013; Ghizoni, Mendes e Corgozinho, 2013).

Destarte, apresenta-se o objetivo deste estudo, que é apresentar práticas clínicas, nos diversos contextos de trabalho, realizadas recentemente de norte a sul do Brasil. Pretende-se apresentar estas práticas brasileiras situando as singularidades de cada situação de trabalho e suas implicações sobre o fazer clínico, entendido como um processo em permanente construção, cujos avanços teóricos são referenciados na análise do empírico.

\section{O MÉTOdo NA CLÍNICA do TRABALHO: CONTRIBUiÇÕES E AVANÇOS DA PSICODINÂMICA DO TRABALHO}

No que se refere ao método, a clínica Psicodinâmica do Trabalho se desenvolve em três etapas: a pré-pesquisa, a pesquisa propriamente dita e a validação (Dejours, 2011). Ghizoni, Mendes e Corgozinho (2013) delineiam estas etapas.

A trajetória da Psicodinâmica do Trabalho, no Brasil, não tem sido somente de replicações do método original do Dejours (2011). Há um significativo número de estudos em Clínica Psicodinâmica do Trabalho com diversas adaptações metodológicas, o que infere haver uma realidade empírica brasileira diferenciando-se da francesa, mas sem sair dos meandros teóricos da Psicodinâmica do Trabalho.

Ghizoni, Mendes e Corgozinho (2013) pontuaram estas diferenças metodológicas, ao verificar que das 37 práticas clínicas encontradas, 18 eram replicações do método da Psicodinâmica do Trabalho e 19 eram adaptações brasileiras a este método. Nessa comparação, as autoras observaram proximidade entre os pressupostos e conceitos, embora o foco teórico tenha sido diferenciado, sendo alguns estudos mais alinhados à ergonomia, outros com a sociologia e os desenvolvidos por Mendes e sua equipe do Laboratório de Psicodinâmica e Clínica do Trabalho da UnB, dando ênfase à realidade brasileira.

Modificações na metodologia para a condução da Clínica Psicodinâmica do Trabalho, foram propostas por Mendes e Araujo (2012), mas mantiveram os referenciais teóricos desenvolvidos por Christophe Dejours. Estas autoras destacaram a importância de alguns dispositivos clínicos como a demanda, a elaboração e perlaboração, a construção de laços afetivos, a interpretação e a formação clínica. Também apresentaram dez condições delineadoras para os procedimentos da clínica: organização da pesquisa; construção e análise da demanda; instituição das regras de conduta do coletivo de pesquisa e do coletivo de 
supervisão; constituição do espaço da fala e da escuta; estruturação do memorial; restituição e deliberação; diário de campo e registro dos dados; supervisão; apresentação dos relatos e avaliação.

Mendes e Araujo (2012) criaram ainda, para a análise dos dados coletados durante as sessões coletivas com os trabalhadores, a Análise Clínica do Trabalho - ACT, que é composta de três etapas: análise dos dispositivos clínicos, análise da psicodinâmica do trabalho e análise da mobilização do coletivo de trabalho.

Ressalta-se que nas adaptações brasileiras há uma preocupação com a escuta clínica, como se observa na Psicanálise (Ghizoni, Mendes e Corgozinho, 2013). Essa escuta clínica exige do clínico ir além do ouvir para escutar aquilo que não é dito, que pode se manifestar, por exemplo, pelo silêncio e pelo vazio, ao se falar do sofrimento no trabalho (Mendes e Araujo, 2012).

Neste sentido, o pesquisador-clínico, como proposto pelo método original, desliza para uma posição de clínico-pesquisador e a pesquisa/ação torna-se uma prática indissociável e constituinte do processo de escuta. A ação vai além dos princípios da fala como ato do agir sobre a organização do trabalho, envolvendo a relação entre a subjetividade do clínico na escuta e a mobilização subjetiva do coletivo (Ghizoni e Mendes, 2014; Ghizoni, 2013).

Como se poderá ver nas práticas clínicas que aqui serão relatadas, cada realidade local ou organizacional impõe ajustes metodológicos. A primeira prática é um recorte de uma pesquisa de doutorado vinculada ao LPCT/UnB e teve por objetivo promover o espaço para a discussão do sofrimento de catadores de materiais recicláveis, vislumbrando a mobilização subjetiva do grupo. A segunda prática clínica foi realizada com servidores de uma escola pública de trânsito no Distrito Federal. O objetivo foi compreender a Psicodinâmica do Trabalho dos profissionais que atuam com educação de trânsito e investigar as ações utilizadas por eles para lidar com a organização do trabalho, assim como a mobilização para se engajar no trabalho.

As práticas clínicas subsequentes foram desenvolvidas pelo coletivo de clínicos vinculado ao Laboratório de Psicodinâmica do Trabalho da Universidade Federal do Amazonas e foram realizadas em instituições públicas de Manaus. A última prática clínica a ser apresentada aqui é uma interface de aplicação da Clínica do Trabalho, que está sendo realizada por meio do Programa de Atenção e Valorização do Servidor - PROSER, com os servidores de diversas secretarias de estado do Rio Grande do Sul. Nesse contexto, apresenta- 
se, a seguir, as práticas clínicas desenvolvidas em Palmas-TO, Brasília-DF, Manaus-AM e Porto Alegre-RS.

\section{RELATOS DAS PRÁTICAS CLÍNICAS}

\subsection{Clínica psicodinâmica da cooperação com catadores de materiais recicláveis}

Objetiva-se, neste relato, apresentar uma prática em Clínica Psicodinâmica da Cooperação, realizada em Palmas, capital do Tocantins, no ano de 2012. Partiu-se do aporte teórico da Clínica Psicodinâmica do Trabalho, no que tange à Clínica da Cooperação baseada em Mendes e Araujo (2012) e da vivência da pesquisadora com um grupo de catadores de materiais recicláveis, que são vinculados a uma organização de trabalho: a Associação de Catadores e Catadoras de Materiais Recicláveis da Região Centro Norte de Palmas-TO (ASCAMPA), que existe desde 2005.

Nesta prática clínica, aconteceram 12 sessões, além de uma reunião inicial, antes das sessões, como forma de convite e de exposição da clínica. Houve também uma reunião final para apresentação e discussão dos dados levantados na clínica e uma reunião de avaliação nove meses após esta reunião final.

Participaram das sessões 16 catadores (dos 34 associados) sendo 9 homens e 7 mulheres, além de 2 jovens auxiliares do Administrador, que não são catadores nem associados. A idade dos catadores variou entre 39 e 78 anos, sendo a média de idade 54 anos. A maioria possui poucos anos de escolaridade.

A condução da clínica, com algumas adaptações, seguiu as recomendações de Mendes e Araujo (2012) em relação às etapas que o pesquisador deve considerar na construção do espaço de discussão, durante as sessões coletivas com os trabalhadores. Esses itens são apresentados a seguir.

1. Organização da pesquisa: Considerou-se a relação existente entre a pesquisadora responsável por esta prática clínica e os catadores, via projetos executados com este público, desde 2007, pelo Núcleo de Economia Solidária - NESol. Fez-se análise documental e observações sobre o trabalho dos catadores a partir das visitas realizadas à Sede da ASCAMPA e na residência de alguns catadores que guardavam os documentos da Associação. 
2. Construção e análise da demanda: A queixa inicial partiu de três catadores membros da diretoria da ASCAMPA que vivenciavam, no dia a dia, a desunião dos catadores e a preponderância do individualismo sobre as ações coletivas e solidárias a que a própria Associação se propunha. Constatou-se o desejo de um grupo pequeno de constituir uma nova cooperativa.

3. Instituição das regras de conduta do coletivo de pesquisa e do coletivo de supervisão: Criaram-se dois coletivos. Um de pesquisa composto pela pesquisadora responsável, uma estagiária estudante de Psicologia e os catadores da Associação. O outro coletivo era de clínicos, composto pela pesquisadora responsável pela prática clínica, a estagiária, a orientadora do estudo e uma psicóloga.

4. Constituição do espaço da fala e da escuta: São as sessões de clínica em si compostas pelo coletivo de pesquisa. A clínica é a personificação de um espaço para a fala e para a escuta. A observação clínica e a interpretação são inerentes a este espaço. Entende-se por interpretação o ato de investigar os diversos significados das falas, dos gestos, das posturas, dos tons de voz. A interpretação foi feita durante a sessão e, sobretudo, após a sessão, pelo coletivo de clínicos em supervisão, conforme recomendam Mendes e Araujo (2012).

5. Registros de dados: a) gravação do áudio (após autorização dos participantes), b) Diário de campo, c) Transcrição da sessão, d) Supervisão e e) Construção do memorial. Os registros são essenciais nesta prática clínica, pois a transcrição da sessão, feita antes da Supervisão semanal, servia de documento para discussão do coletivo de clínicos, assim como o diário de campo, um documento mais pessoal do pesquisador, com os registros da sua emoção, dúvidas, dores, entre outros. Na Supervisão, os dados são contrastados e originam o memorial, que é o produto deste registro, o qual é lido/discutido na sessão subsequente.

6. Apresentação dos relatos na reunião final: feito no formato de pôster para que os catadores pudessem visualizar os avanços tanto na forma escrita quanto com imagens (fotos). Os resultados foram divididos em cinco momentos, para que compreendessem os avanços durante as sessões: das queixas, passando para as discussões e deliberações.

7. Avaliação da Clínica: realizada por meio de uma entrevista coletiva com os catadores, nove meses após a reunião de apresentação e discussão dos resultados da Clínica. Aconteceu na nova sede da Associação. Contou com a participação de 9 catadores (dois são novos na ASCAMPA) e da Estagiária que acompanhou a Clínica Psicodinâmica da Cooperação.

Os resultados desta prática clínica reverberaram tanto nos catadores quanto na pesquisadora. Afetar-se pela fala dos trabalhadores foi uma constante neste estudo. Assim, 
vivenciar a observação clínica teve momentos de dúvida, dor e alegria. Uma forma de falar destes sentimentos advindos das sessões foi transcrevê-los tanto nos diários de campo, para discussão em supervisão, quanto nos memoriais, para que os catadores também soubessem destes sentimentos. Esta estratégia favoreceu a quebra da hierarquia, do lugar do suposto saber, uma questão pontuada em supervisão.

O grupo de catadores conseguiu fazer a passagem do espaço de discussão para as deliberações, elemento essencial para a mobilização subjetiva se concretizar. Nessa prática, as deliberações começaram a acontecer na décima sessão, observando-se que as sessões $7^{\mathrm{a}}$ e $8^{\mathrm{a}}$ foram essenciais para a discussão dos grandes problemas com a gestão da sede. Estas discussões reverberaram nas deliberações, que culminaram na criação de um coletivo gestor de sete pessoas para atuar na sede da ASCAMPA. Criaram regras de convivência, regras para a realização das tarefas, dos horários e distribuição de atividades.

Verificou-se que se constituindo o espaço de fala e de escuta para se conhecer o trabalho do outro, tendo o fazer como categoria central, a coragem pode vir à tona e os enfrentamentos aconteceram, como foi o caso dos catadores da ASCAMPA.

Acessou-se diretamente a organização do trabalho ao se fazer a escuta dos medos e angústias sobre o trabalho, ou seja, ao nomearem os seus sentimentos de sofrimento em relação ao trabalho na Associação, puderam colocar a inteligência prática em ação, assim como a cooperação e o reconhecimento, elementos essenciais da mobilização subjetiva

Viveu-se, assim, a provisoriedade da Clínica, um elemento pontuado por Mendes e Araujo (2012), pois tudo está por ser construído, tudo é um vir a ser. Tudo vai depender do real vivido neste espaço de fala e escuta. Percebe-se que este real da organização do trabalho pode continuar após a Clínica se o grupo estiver engajado, mobilizado. A manutenção de espaços de discussão promovidos pelos próprios trabalhadores é um elemento importante para que a mobilização subjetiva persista.

Na reunião de avaliação, nove meses após a prática clínica e sem a presença ou interferência do coletivo de clínicos neste período, notou-se que os avanços se referiam ao controle administrativo-financeiro da ASCAMPA; a apropriação do saber; ao empoderamento. Os desafios percebidos naquele momento diziam respeito: às dificuldades com a construção e discussão das regras de funcionamento na nova Sede; aos pagamentos por função (por produção ou coletivamente); às diferenças individuais e à falta de um espaço para discussão. 
Ao se concluir a tese, em outubro de 2013, fez-se uma apresentação formal aos catadores, na nova Sede da Associação e pactuou-se a necessidade de outros projetos que envolvessem a organização das questões administrativas e financeiras da Associação. Assim, uma estudante do Curso de Administração da Universidade Federal do Tocantins-UFT começou, neste mesmo mês, um estágio extra curricular na ASCAMPA. Em agosto de 2014, iniciou-se um projeto de pesquisa, via PIBIC/UFT, focado na Gestão da Associação. Dessa forma, desde esta data, presta-se uma Assessoria Técnica a Diretoria da ASCAMPA, via NESol/ITCP/UFT, com projetos de Pesquisa e Extensão incluindo os saberes dos alunos da graduação com os fazeres dos catadores.

\subsection{Clínica psicodinâmica do trabalho com servidores de uma escola pública de trânsito}

Este estudo foi realizado com os servidores de uma Escola Pública de Trânsito de Brasília-DF, cuja principal atividade é o atendimento ao público. O objetivo foi compreender a Psicodinâmica do Trabalho dos profissionais que atuam com educação de trânsito e investigar as ações utilizadas por eles para lidar com a organização do trabalho, assim como a mobilização para se engajar no trabalho.

O método utilizado foi a clínica Psicodinâmica do Trabalho, que se baseia na construção de um espaço de discussão, com sessões coletivas com os trabalhadores. Objetivou-se, com essa clínica, dar liberdade de expressão aos trabalhadores para que falassem sobre o seu trabalho.

A clínica seguiu as condições e procedimentos propostos por Mendes e Araujo (2012). Foram feitas sete sessões, que tiveram a duração de uma hora e meia, no local de trabalho dos servidores. Os encontros aconteceram por um período de três meses com dez servidoras.

Os resultados foram organizados de acordo com a organização do trabalho, a mobilização subjetiva, o sofrimento, as defesas e as patologias. Além disso, analisou-se o coletivo de trabalhadores e a presença dos gestores no espaço de discussão.

Em relação à organização do trabalho, observou-se que o servidor aprende com a prática. À medida que as situações vão surgindo, os servidores antigos vão ensinando os mais novos. Devido a isso, a pessoa que tem mais conhecimento é mais consultada e acaba assumindo o papel de líder.

No atendimento, o servidor precisa dar uma resposta imediata, pois o usuário quer sair com seu problema resolvido. O servidor deve saber lidar com a frustração de não conseguir ajudar o outro, com os erros e com as artimanhas dos usuários. Deve ter paciência com as 
pessoas que têm dificuldade de entender as informações dadas e ter boa capacidade de atenção e concentração.

Durante o dia, há momentos em que a demanda é maior e em outros, menor. Alguns procedimentos são mais fáceis e outros mais demorados. Além disso, as servidoras desenvolvem muitas atividades ao mesmo tempo, como atender o usuário pessoalmente e dar informação por telefone. Esse duplo papel de atender e lançar os dados no sistema faz com que as servidoras errem. Por isso dividem as tarefas entre si: uma atende e outra lança os dados no sistema. Fazem revezamento entre as funções, para que todas dominem as atividades.

No que se refere à mobilização subjetiva, percebe-se que a relação das servidoras com os usuários ocorre de forma conflituosa e de forma harmônica. Busca-se ajudar o usuário, fazendo além das obrigações, o que ajuda a inibir o comportamento agressivo dele.

As servidoras têm liberdade para desenvolver suas habilidades e deixar sua marca pessoal no que fazem. Podem utilizar a sensibilidade e a inteligência para transformar o trabalho e a organização. Há cooperação pelo vínculo de amizade e pelo profissionalismo. A boa convivência com as colegas gera satisfação, companheirismo e comprometimento.

As servidoras têm autonomia para decidir como proceder em relação aos usuários e procuram não sobrecarregar os gestores sem necessidade. Para acalmá-los e satisfazer o desejo deles de falar com a chefe, sem incomodá-la, as servidoras se passam por chefe. "Já impõe respeito". "Qualquer um que chega ali e fica em pé, eles acham que é chefe".

Quanto ao sofrimento, às defesas e às patologias, nota-se que as servidoras são atingidas pelos constrangimentos que sofrem no trabalho e que influenciam a vida pessoal. As servidoras ficam chateadas com aborrecimentos no trabalho.

Consideram que há sofrimento nas seguintes situações: para aprender a tarefa; no "retrabalho", ou seja, ter que ficar refazendo os projetos; nos empecilhos e imprevistos que impedem a conclusão das tarefas; em não ter o domínio de todas as etapas de execução do trabalho e na relação com os usuários. Além disso, o servidor não pode chegar atrasado e tem dificuldade de sair de seu posto de trabalho porque o usuário quer ser atendido e reclama.

Diante do sofrimento, as servidoras desenvolvem estratégias de defesa. A racionalidade é constantemente usada para se analisar as condições de trabalho. As servidoras buscam ver as vantagens e as gratificações do trabalho como forma de tolerar o sofrimento. Às vezes, brincam umas com as outras para não absorver os aborrecimentos com os usuários, pois ouvem coisas desagradáveis. Aprenderam, ainda, 
a não se intimidar com a grosseria dos usuários e a distinguir quando devem dar ou não atenção a eles.

O trabalho de atendimento gera danos físicos e psicossociais. A agressividade dos usuários deixam os servidores abalados emocionalmente. Também há sobrecarga de trabalho gerada pela falta de servidores e pela quantidade de tarefas.

No que se refere ao coletivo de trabalho, observou-se que os acordos e decisões sobre o trabalho variam de acordo com a necessidade de cada dia. Existe a oportunidade de se propor mudanças no trabalho e de se alterar a forma de execução dos procedimentos.

Na clínica, é comum os gestores participarem do espaço de discussão. O que irá definir o resultado da presença dos gestores nesses encontros será a relação estabelecida entre os gestores e servidores, que poderá ser de confiança ou não. Como disse uma gestora: "Se eu não participo, as meninas podem ficar mais à vontade, mas também se eu não participo, eu não vou ter a possibilidade de ouvi-las”.

\subsection{Experiência em Clínicas psicodinâmicas da Cooperação com trabalhadores de uma instituição de ensino federal no Amazonas}

A experiência de clínica do trabalho com os técnicos-administrativos surgiu a partir de uma escuta do gestor do setor em questão demandada à psicóloga educacional da referida instituição. Tal profissional era associada ao grupo do Laboratório de Psicodinâmica (LAPSIC) da Faculdade Psicologia da UFAM e articulou uma reunião entre o gestor e os membros do LAPSIC, em que foi esclarecida a proposta da clínica do trabalho e realizou-se uma pré-análise, na qual sete trabalhadores - de um total de doze - concordaram em participar da clínica. Levou-se em conta o interesse do coletivo de trabalhadores, o apoio da gestão em liberar os trabalhadores e o caráter empírico da aplicação da clínica em uma instituição pública de ensino para o coletivo de pesquisadores.

A clínica do trabalho, que se configurou como uma clínica da cooperação (Mendes e Araujo, 2012), ocorreu no período de abril a junho de 2012, com periodicidade semanal e duração de uma hora, em aproximadamente 12 sessões. A última sessão foi a apresentação da devolutiva ao gestor, assunto de grande interesse para os trabalhadores que viram na clínica a oportunidade de estreitar o diálogo. Essa devolutiva foi marcada pelo estranhamento do gestor em relação à vivência de sofrimento dos trabalhadores pela falta de prescrição do trabalho. Destaca-se o paradoxo da autonomia, visto pelos trabalhadores tanto como desencadeador de 
sofrimento como mobilizador de prazer e que, para eles, tinha estreita relação com a falta de prescrição do trabalho.

Um desdobramento dessa clínica favoreceu o estabelecimento de reuniões mensais, denominadas de clínica de monitoramento, que se estenderam por mais três meses. O coletivo de pesquisadores atuou como mediador nas relações socioprofissionais, que foram vistas como outro importante desencadeador de sofrimento. Esse tema foi abordado durante as sessões da clínica da cooperação (Mendes e Araujo, 2012).

O real da clínica se revelou pela desistência de duas trabalhadoras, pela ausência de uma trabalhadora pelo período de um mês e por uma greve dos trabalhadores das universidades federais.

Apesar de tais dificuldades, o coletivo de trabalhadores conseguiu perlaborar, avançando na elaboração de um sofrimento criativo e construindo estratégias de enfrentamento, que indicam que esse coletivo estava caminhando para a ressignificação do sofrimento. Observou-se, nesse coletivo, um movimento para dar corpo à Mobilização Subjetiva. Apesar desses ganhos, o coletivo de trabalhadores se mostrou resignado e negava o sofrimento, o que impossibilitou maior aprofundamento na construção de estratégias de enfrentamento.

\subsection{Oficina de escuta clínica do trabalho de professores de que atuam em educação inclusiva em Manaus.}

$\mathrm{O}$ relato apresenta o recorte de uma pesquisa de mestrado que teve como objetivo compreender as vivências de prazer-sofrimento de professores que atuam com educação inclusiva, em Manaus, a partir da análise dos processos psicodinâmicos do trabalhar. O campo empírico foi o Complexo de Educação Especial em Manaus. O presente estudo focaliza a organização do trabalho e seus desdobramentos.

O aporte teórico utilizado foi o da Psicodinâmica do trabalho. A metodologia recorreu à escuta clínica do trabalho, realizada em reuniões grupais, caracterizadas como oficinas, inspiradas nos pressupostos da psicodinâmica, recorrendo secundariamente às técnicas do grupo operativo (Martins, 2009).

O espaço coletivo de discussão, proporcionado pela prática da pesquisa em intervenção grupal, favorece os processos de elaboração e perlaboração das situações vivenciadas no trabalho. Dessa forma, contribui para a criação dos modos de resistência dos trabalhadores à dominação estabelecida nos processos de gestão da organização do trabalho, 
estabelecendo assim as estratégias que contribuem para a conquista da saúde mental no trabalho (Martins \& Mendes, 2012).

Os participantes da pesquisa foram vinte e cinco professores que atuam com educação inclusiva no sistema de ensino municipal de Manaus, integrantes do quadro efetivo da Secretaria Municipal de Educação de Manaus - SEMED. O grupo foi composto por cinco homens e vinte mulheres, com o tempo de serviço diversificado: de seis meses (recémcontratados) a 20 anos. Todos os professores tinham em sua sala de aula um aluno com algum tipo de deficiência.

As oficinas foram realizadas quinzenalmente ao longo de três meses, totalizando sete encontros, que tiveram duração aproximada de três horas. Os dados foram coletados a partir da fala, que foi gravada; e da observação clínica. Esta configurou-se como um instrumento importantíssimo para a significação das falas.

No primeiro encontro foi estabelecido um "contrato" com o grupo acerca do compromisso ético da pesquisa, do sigilo e do respeito com as falas de cada participante. Em seguida, foi aplicada uma dinâmica de apresentação, com o objetivo de promover a sensibilização e socialização do grupo.

Nas demais sessões foram realizadas dinâmicas voltadas para as vivências subjetivas de trabalho, com o objetivo de facilitar a circulação da palavra. A cada encontro, realizava-se a leitura do memorial da sessão anterior, que também desencadeava uma nova discussão.

Na sétima sessão foi realizada uma devolutiva para os participantes. Os resultados do estudo foram submetidos à validação do grupo e promoveram a reflexão. Houve também a realização de uma palestra com os gestores, em que foi apresentado e entregue um relatório contendo sugestões e recomendações.

Passando aos resultados da análise da Organização do Trabalho no Complexo Municipal de Educação Especial - CMEE, destaca-se que é o responsável pela promoção da educação dos alunos atendidos pela educação inclusiva. As atividades englobam ações pedagógicas e atendimentos especializados, visando à inclusão social e escolar de alunos com deficiência (física, intelectual e sensorial), transtornos globais do desenvolvimento e altas habilidades/superdotação. Insere-se também a formação continuada dos professores que atuam com educação inclusiva.

O principal público do CMEE são crianças com idade entre 0 e 14 anos, que apresentam os seguintes diagnósticos: deficiência visual parcial (baixa visão ou visão 
subnormal), cegueira, surdez, deficiência mental, deficiências múltiplas, deficiência física, distúrbio de comportamento, altas habilidades, autismo, síndrome de Down, entre outros.

A equipe é composta por psicólogos, fonoaudiólogos, fisioterapeutas, assistentes sociais, pedagogos, psicopedagogos, que realizam um acolhimento inicial à família e aos participantes, informando o funcionamento do complexo e as possibilidades de atendimento. Além disso, a equipe realiza uma avaliação. A partir da discussão dos atendimentos, são realizados os possíveis direcionamentos que contemplam atividades que acontecem dentro da estrutura do complexo, na rede municipal de ensino, além de encaminhamentos à rede de saúde, assistência social e jurídica. Como resultado desse processo avaliativo, são desenvolvidas as potencialidades dos alunos com necessidades educacionais especiais, promovendo a inclusão de grande parte no ensino regular e com o suporte de salas de recursos e sala multifuncional, em que há o apoio da equipe do núcleo psicopedagógico.

Todavia, existe uma considerável distância entre o prescrito e o real. Nem todas as escolas da rede municipal são equipadas e preparadas para receber crianças com deficiência. Os critérios para encaminhar o aluno com deficiência para uma escola são: 1) proximidade da residência do aluno; 2) se a escola possui sala de recurso multifuncional; 3) se a escola possui algum professor que tenha participado do mini-curso "Sensibilizar para incluir"; 4) se já possui em seu quadro de alunos, algum tipo de deficiência.

Quando a situação foge aos critérios estabelecidos, a criança é encaminhada para a escola mais próxima de sua residência. Nesse caso, compete ao CMEE enviar a equipe psicopedagógica para a escola e conduzir o curso "Sensibilizar para incluir", que tem duração de 20 horas. Todavia, algumas escolas se recusam a receber os alunos, apesar da obrigatoriedade legal; o que gera conflitos entre as escolas e os pais das crianças.

A partir da devolutiva, a gestora de educação especial incluiu, no calendário de formação de professores, oficinas de discussão das vivências do trabalho com todas as escolas que atuam com educação inclusiva. As oficinas alcançaram 150 professores, com grupos formados por 30 pessoas. Cada grupo teve três encontros, com duração em média de 3 horas. Houve também intervenção em 10 escolas, objetivando a escuta dos professores, seguindo os mesmos métodos da pesquisa, com a prática de dinâmicas e discussões acerca do trabalho.

Esse estudo evidenciou o real do trabalho na educação inclusiva, apresentando as contradições entre trabalho prescrito e o real. A falta de prescrição é um dos principais desencadeadores de sofrimento nesse trabalho. Entretanto, esta não paralisa os professores. Diante das adversidades, buscam se organizar e criar regras de ofício. 
Outras formas de enfrentamento são: buscar informações na internet e em outros meios, o que evidencia a mobilização subjetiva e o exercício da inteligência prática em seu fazer. Percebeu-se, ainda, que os professores se esforçavam e investiam muita energia, e até mesmo paixão no trabalho. Entretanto, na maioria das vezes, seu investimento passa desapercebido, pois não recebem reconhecimento da sociedade, o que se torna uma fonte de sofrimento. O reconhecimento mostrou-se decisivo na dinâmica da mobilização subjetiva.

Analisando os avanços propiciados pelas oficinas de escuta clínica do trabalho, podese depreender que houve um processo de transformação no discurso e na ação destes professores. As queixas iniciais se relacionavam à falta da aplicabilidade da legislação, à falta de recursos e de parceria da família, sinalizando o não querer assumir a responsabilidade diante da inclusão escolar. Entretanto, de forma velada, manifesta-se o medo de não saber fazer, a insegurança diante do desconhecido, do temor de fracassar. No entanto, o espaço da fala proporcionou a transformação deste posicionamento em direção à responsabilidade conjunta; no sentido de assumir a inclusão como uma ação no seu fazer a partir da mobilização e da cooperação.

\subsection{A experiência do coletivo de clínicos em um programa estadual de atenção e valorização dos servidores}

Este relato parte de uma experiência desenvolvida junto as Clínicas descritas como do Trabalho, vivenciadas desde 2002 através do Programa de Atenção e Valorização do Servidor - PROSER (decreto 48.898 de 06 de março de 2012), que tem a finalidade de coordenar e integrar ações e programas nas áreas de assistência à saúde, promoção, prevenção e acompanhamento a saúde física e mental dos servidores. É constituído por servidores clínicos provenientes de diversas secretarias e Órgãos de estado do Rio Grande do Sul - Casa Civil, Secretaria da Saúde, Educação, Segurança Pública, Administração e Recursos Humanos, de Políticas para as Mulheres, da Fazenda, DETRAN, Instituto de Previdência do Estado; sendo direcionado aos próprios servidores.

Os prejuízos à saúde dos servidores são determinados por fatores multicausais em que estão presentes fatores individuais, coletivos, sociais e institucionais. O crescente número de afastamentos do trabalho denuncia o enfraquecimento das estratégias coletivas, sendo que nesta lacuna estão surgindo basicamente as saídas individuais diante do sofrimento, gerando assim maior adoecimento e medicalização. 
A metodologia das Clínicas do Trabalho, dentre elas a da Psicodinâmica do Trabalho, se apresentam como possibilidade de pensar para além dos sintomas e do âmbito do indivíduo, desmistificando algumas máximas institucionais que contribuem na perda do sentido do trabalho para o trabalhador levando ao desengajamento afetivo necessário a mudanças na organização do trabalho.

Para que o programa se sustentasse internamente foi necessário respeitar especificidades de diferentes secretarias que compõe o programa, uma vez que, evidenciam-se diferentes processos de trabalho, mas regidos por uma mesma forma de organização. Assim foi necessário compor, com diversas nuances da Clínica do Trabalho, a adaptação de acordo com a realidade de cada núcleo respeitando singularidades e diretrizes. Em alguns casos, acoplaram-se a serviços já existentes e em outros, criaram-se novos.

Diante desta diversidade seria fundamental aprender a trabalhar em coletivo e para isso seria necessário a criação e manutenção de vínculos mais solidários entre os participantes que possibilitassem realizar esta experiência. Foram feitas duas vivências de imersão em que foram trabalhados vínculo e confiança entre os participantes do programa. Depois disso, o grupo adquiriu uma maturidade que possibilitou a criação de diversos grupos de trabalho temáticos. Esses grupos trabalham de forma complementar em que os resultados são compartilhados com todos participantes do grupo estendido.

Percebeu-se que só depois da estruturação do coletivo de trabalho foi possível uma melhor compreensão da sua importância como elemento estrutural para a saúde mental dos servidores atendidos. Essa etapa durou aproximadamente um ano e meio e foi estratégica para o avanço do Programa, caracterizando-se como um processo contínuo.

Depois de experienciar as próprias fragilidades e limitações foi possível realizar supervisões entre o próprio grupo de coordenadores de núcleos, reforçando a prática da escuta e da construção de saúde, desviando de algumas capturas institucionais, o que tem sido um grande aprendizado a todos.

Após a consolidação interna, conquistou-se a representação de cinco participantes do PROSER na Conferência Macrorregional de Saúde do Trabalhador de Porto Alegre e ainda, a assinatura de um termo de adesão dos secretários de estado envolvidos, com o compromisso de continuidade e atenção em relação ao servidor. Nesta direção, os profissionais também estão tecendo redes com a Ouvidoria Geral do Estado.

Os clínicos entendem que o caminho ainda está sendo trilhado e que existem muitas questões abertas, dentre elas a troca de governo, mas tem também a conviç̧ão de que este 
coletivo não será facilmente desfeito. Compreendem que através desta potência coletiva terão melhores condições de tornar o PROSER um programa de estado e não apenas de governo.

\section{DESAFIOS NO CAMPO DAS PRÁTICAS EM CLÍNICA PSICODINÂMICA DO TRABALHO}

As experiências relatadas evidenciam a diversidade de demandas e a importância da escuta clínica do sofrimento do trabalho. Os relatos indicam que a distância entre o prescrito e o real, que desencadeia sofrimento, também está presente no fazer dos pesquisadores, demandando mobilização e criação de alternativas adequadas a cada realidade.

Uma dimensão relevante, apontada nas pesquisas, foi a importância do espaço da fala. Em todos os estudos, a coleta e a validação de dados foram realizadas em reuniões coletivas, que se constituem como um espaço em que os grupos de trabalhadores encontram a possibilidade de falar da dimensão subjetiva de seu trabalho. Ao falar, escutar os colegas e refletir, no espaço coletivo, os trabalhadores acabam por ampliar sua percepção e sua compreensão do trabalhar, expandindo seu poder de agir sobre as condições que agravam o sofrimento no trabalho.

A riqueza proporcionada pelo espaço da fala e da escuta permite que se construam os caminhos, de maneira a ressignificar o sentido do trabalhar pela fala. É importante ressaltar que, apesar da organização do trabalho ter diversas facetas a cada modalidade de trabalho, é nela que o real do trabalho é revelado e é, diante deste fracasso do trabalho, que o coletivo necessita reconstruir os laços.

Destaca-se, em todas as pesquisas, a busca dos trabalhadores por algum tipo de suporte para enfrentar as questões impostas pela organização do trabalho, fortemente influenciada pela precarização do trabalho. Há uma demanda reprimida de trabalhadores em sofrimento psíquico. Por meio da clínica Psicodinâmica do Trabalho, abre-se espaço para a elaboração e perlaboração dos trabalhadores. Em geral, os trabalhadores gostam da ideia de poder discutir/refletir sobre o trabalho e, em alguns casos, o sofrimento está tão intenso que a fala funciona como catarse. A escuta dos clínicos-pesquisadores, nesse momento, é vital, jamais será neutra, mas sempre "arriscada" (Martins e Mendes, 2012, p. 175).

Os relatos apontam para a cooperação como um dos caminhos privilegiados para resistir à dominação e investir na busca de emancipação no trabalho. Toda cooperação para 
regular a organização prescrita de trabalho contém uma dimensão emancipatória, pois os trabalhadores podem mudar o que foi proposto pela hierarquia.

Assim, a clínica psicodinâmica do trabalho tem funcionado, antes de tudo, como recuperação dos laços de cooperação, fortemente esfacelados pela precarização do trabalho. Nas sete práticas aqui relatadas, houve um retomar da cooperação, do reconhecimento, da confiança, da solidariedade. Dependendo do coletivo de trabalhadores e da organização do trabalho, esse retomar foi superficial, outras vezes mais profundo. Chama a atenção a fragilidade dos laços de cooperação atualmente vigentes no mundo do trabalho e que necessitam ser retroalimentados incessantemente!

As organizações do trabalho, por mais que sejam aparentemente rígidas, se movimentam, se transformam porque são feitas por pessoas (Dejours, 2011; Moraes, 2011). Por isso, considera-se que a clínica tem propiciado transformações quando abre espaço para a fala dos trabalhadores e a escuta feita tanto pelo pesquisador-clínico (ou clínico-pesquisador) como pelos demais trabalhadores participantes da clínica.

O resgate da cooperação se mostra como um caminho para a reorganização do trabalho, haja vista a distância entre o prescrito e o real. Nesse sentido, o trabalho também apresenta o potencial de atuar como mediador da emancipação. A Clínica Psicodinâmica do Trabalho oferece espaço interno de fala e escuta qualificada, que permite repensar a organização de trabalho e propor mudanças.

A dimensão política da clínica do trabalho fica mais evidente a partir do espaço de deliberação, que promove a emancipação. Valorizar a experiência, a partir da fala do real do trabalho, refaz o caminho da conscientização. A análise das situações de trabalho favorece a renovação da capacidade de pensar e para o agir coletivo, que é uma via para a emancipação do sujeito no trabalho. Essa emancipação do trabalhador é o propósito central da clínica do trabalho, para o qual as diferentes práticas clínicas aqui relatadas contribuíram, embora algumas questões ainda reflitam os desafios enfrentados pelos clínicos do trabalho.

Um deles diz respeito aos dispositivos clínicos usados para escuta clínica do sofrimento. Uma pergunta central orienta essas inquietações: como mobilizar os sujeitos para a construção das deliberações? Todos os dispositivos usados nessas práticas são importantes para essa passagem, mas ainda não são suficientes. Uma dimensão que tem se mostrado muito potente para mobilizar essa passagem é a transferência e a supervisão clínica. Desse modo, propõe-se como agenda de pesquisa revisitar os dispositivos que vem sendo usados, levando em consideração as contribuições da psicanálise, que referencia a proposta de uma clínica 
analítica do trabalho, na qual são considerados como dispositivos a demanda, a transferência e a interpretação. Essa proposta encontra-se delineada em Mendes, Moraes e Merlo (2014), podendo constituir um ponto de partida para repensar as práticas em clínica do trabalho e orientar futuras pesquisas.

\section{REFERÊNCIAS}

BENDASSOLLI, P. F e SOBOLL, L. A. P. (Orgs). 2011. Clínicas do Trabalho: novas perspectivas para a compreensão do trabalho na atualidade. São Paulo: Atlas. 288 p. DEJOURS, C. 2011. A metodologia em psicodinâmica do trabalho. In S. Lancman, e L. I. Sznelwar (Orgs) In Christophe Dejours: da psicopatologia à psicodinâmica do trabalho (Tradução: Franck Soudant). Rio de Janeiro: Ed. Fiocruz; Brasília: Paralelo 15, 3ª . Ed, 2011. Cap. 2, p. 125-150.

DEJOURS, C. 2012. Trabalho e emancipação. Brasília: Paralelo 15, 221 p.

DEJOURS, C. e MOLINIER, P. 2011. O trabalho como enigma. In S. Lancmane L. Sznelwar. (Orgs.), Christophe Dejours: da psicopatologia à Psicodinâmica do Trabalho. (3 ed. rev, F. Soudant; S. Lancmane L. I. Sznelwartrads). Rio de Janeiro: Fiocruz Brasília: Paralelo 15, p. 151-166

GHIZONI, L.D. 2013. Clínica Psicodinâmica da Cooperação na Associação de Catadores e Catadoras de Materiais Recicláveis da Região Centro Norte de Palmas - TO (ASCAMPA). Tese de doutorado. Universidade de Brasília, Brasília, DF, Brasil, 308 p. GHIZONI, L. D. e MENDES, A. M. 2014. Dispositivos para uma escuta clínica do sofrimento no trabalho dos catadores de materiais recicláveis. Contextos Clínicos, 7(1),15-26. GHIZONI, L. D., MENDES, A. M. e CORGOZINHO, J. P. 2013. Uma proposta brasileira para a Clínica Psicodinâmica do Trabalho. In L. D. C. Schlindwein (Org.). Saúde mental e trabalho na Amazônia: múltiplas leituras sobre prazer e sofrimento no trabalho. Vol I, Porto Velho-RO: EDUFRO, p. 25-39.

GOVERNO DO ESTADO DO RIO GRANDE DO SUL. Decreto $n^{\circ} 48.898$, de 6 de março de 2012.

MARTINS, S. R. 2009. Clínica do trabalho. Coleção Clínica Psicanalítica. São Paulo: Casa do Psicólogo. 195 p.

MARTINS, S. R. e MENDES, A. M. 2012. Espaço coletivo de discussão: a clínica psicodinâmica do trabalho como ação de resistência. Revista Psicologia, 12(2), 171-183. MARTINS, S. R., BOTTEGA, C. G., VASCONCELOS, A. C. L., SOBOLL, L. A. P., MORAES, R. D., HORST, A. C.; FACAS, E. e MERLO, A.C. 2013. Construindo identidade: narrativas históricas da psicodinâmica do trabalho no cenário Brasileiro. In: A. R. C. Merlo;

A. M. Mendes e R. D. de Moraes (Orgs.), O sujeito no trabalho: entre a saúde e a patologia. Curitiba, Juruá, p. 25-40.

MENDES, A. M. 2007. Psicodinâmica do Trabalho: teoria, método e pesquisas. São Paulo: Casa do Psicólogo. 368 p.

MENDES, A. M. e ARAUJO, L. K. R. 2012. Clínica psicodinâmica do trabalho: o sujeito em ação. Curitiba: Juruá. 154 p.

MENDES, A. M.; MORAES, R. D. e MERLO, A. R. C. (Orgs.). 2014. Trabalho e

Sofrimento: práticas clínicas e políticas. Curitiba: Juruá. 260 p. 
MOLINIER, P. 2008. A dimensão do cuidar no trabalho hospitalar: abordagem psicodinâmica do trabalho de enfermagem e dos serviços de manutenção. Revista Brasileira de Saúde Ocupacional, São Paulo, 33 (118), 06-16.

MORAES, R. D. 2011. As estratégias de defesa e de enfrentamento do sofrimento no trabalho com automação no Polo Industrial de Manaus. In: M. C. Ferreira; J. S. N. Garcia; C. P. Almeida; A. M. Mendes (Orgs.). Dominação e resistência no contexto trabalhosaúde.1ed.São Paulo: Mackenzie, 2011, v. 1, p. 101-120.

\section{Liliam Deisy Ghizoni}

Professora da Universidade Federal do Tocantins - UFT - Campus Universitário de Palmas, no Curso de Administração. Doutora em Psicologia Social do Trabalho e das Organizações na UnB com Estágio Sanduíche na Université Catholique de Louvain la Neuve - Bélgica. Mestre em Educação (área de Educação e Trabalho) pela Universidade Federal de Santa Catarina. Especialista em Saúde Mental pela FIOCRUZ. Psicóloga pela Universidade do Vale do Itajaí, graduação em Estudos Sociais pela Universidade do Vale do Itajaí. Membro do NESol/ITCP/UFT. Pesquisadora do Laboratório de Psicodinâmica e Clinica do Trabalho LPCT/UnB. Membro dos Grupos de Pesquisa do CNPQ: Psicodinâmica e Clínica do Trabalho (UnB) e Grupo de Estudos e Pesquisas em Gestão Social (UFT).

E-mail: ldghizoni@gmail.com

Endereço: Universidade Federal do Tocantins - UFT -Quadra 109 Norte Av. NS-15, ALCNO-14. Plano Diretor Norte. CEP: 77001-090. Palmas/TO

\section{Solene Nobre de Medeiros}

Mestre em Psicologia Social, do Trabalho e das Organizações pela Universidade de Brasília. Especialista em Psicologia Clínica e Psicologia do Trânsito pelo Conselho Federal de Psicologia. Especialista em Teoria Psicanalítica e em Psicodinâmica do Trabalho pela Universidade de Brasília (UnB). Graduada em Letras e em Psicologia. Servidora pública, psicóloga clínica e clínica do trabalho. Coordenadora do Programa de Preparação para Aposentadoria do DETRAN.

E-mail: solenenobre@globo.com

Endereço: Departamento de Trânsito do Distrito Federal SAM, Lote "A" Bloco "B" Ed. Sede DETRAN/DF - CEP: 70.620-000

\section{Gerusa Menezes de Carvalho}

Mestranda do Programa de Pós Graduação em Psicologia da Universidade Federal do Amazonas, bolsista pela Fundação de Amparo à Pesquisa do Estado do Amazonas (FAPEAM). Psicóloga da Secretaria de Assistência Social e Direitos Humanos de Manaus.

E-mail: gerusa.2509@gmail.com

Endereço: Av. General Rodrigo Otávio Jordão Ramos, 3000 Campus Universitário.

Setor Sul, Bloco X - CEP: 69077-000 - Manaus - AM - Brasil

\section{Rosângela Dutra de Moraes}

Professora da Faculdade de Psicologia da Universidade Federal do Amazonas, integrante do quadro efetivo, nível Associado I. Atuando na graduação e no mestrado em psicologia, na área de Psicologia do Trabalho e Organizacional, com ênfase na teoria psicodinâmica do trabalho. Coordenadora do Laboratório de Psicodinâmica do Trabalho da UFAM. Psicóloga (UFPA); Especialista em Psicologia Clínica (UFPA); Mestra em Educação (UFAM); Doutora em Ciências: Desenvolvimento Sócioambiental (NAEA/UFPA), com doutorado sanduíche na 
Faculdade de Psicologia da Universidade Autônoma de Madrid, Espanha. Pós-doutorado no Conservatoire National des Arts et Métiers - CNAM, Paris. Membro da Associação Nacional de Pesquisa Pós-Graduação em Psicologia. Principais temas de pesquisa: trabalho e saúde, subjetividade e trabalho, transformação do sofrimento do trabalho, clínica do trabalho.

E-mail: rosangeladutra@ufam.edu.br

Endereço: Av. General Rodrigo Otávio Jordão Ramos, 3000 Campus Universitário

Setor Sul, Bloco X - CEP: 69077-000 - Manaus-AM-Brasil

\section{Priscila Moreira Santana}

Mestranda em Psicologia pela Universidade Federal do Amazonas, bolsista pela Fundação de Amparo à Pesquisa do Estado do Amazonas (FAPEAM). Psicóloga com atuação na área Organizacional e do Trabalho.

E-mail: priscilamoreira_psi@ hotmail.com

Endereço: Av. General Rodrigo Otávio Jordão Ramos, 3000 Campus Universitário

Setor Sul, Bloco X - CEP: 69077-000 - Manaus-AM-Brasil

\section{Cláudia de Negreiros Magnus}

Possui graduação em Psicologia pela Pontifícia Universidade Católica do RS (1993); cursou quatro anos de Bacharelado em Artes Cênicas pela Universidade Federal do Rio Grande do Sul (UFRGS). Realizou especialização em Administração de Recursos Humanos (PUC 1997) e em Supervisão de Treinamento Empresarial (PUC - 1999). Fez MBA em Marketing (ESPM - 2000) e em Gestão de Pessoas (ESPM - 2003). Pela UFRGS, cursou Mestrado em Psicologia Social e Institucional, cuja dissertação abordou a saúde dos trabalhadores de saúde mental de hospital psiquiátrico público (2009). Atualmente é aluna de Doutorado desta mesma universidade, participando do grupo de pesquisa do Laboratório de Psicodinâmica do Trabalho coordenado pelo professor Doutor Álvaro Roberto Crespo Merlo. É servidora da Secretaria Estadual de Saúde (SES), lotada no Hospital Sanatório Partenon, em que coordena a Comissão de Saúde do Servidor.

E-mail: cmagnus@psicoonline.com.br

Endereço: Programa de Pós-Graduação em Psicologia Social e Institucional (PPGPSI) - Rua Ramiro Barcelos, 2.777 - Sala 212 - 2º Andar - Cep: 90035-003

\section{Álvaro Roberto Crespo Merlo}

Médico do Trabalho, Especialista em Saúde Pública pela Université Paris I (PanthéonSorbonne) em 1979, Doutor em Sociologia pela Université Paris VII (Denis Diderot) em 1996. Atualmente é Professor Titular da Universidade Federal do Rio Grande do Sul, atua na Faculdade de Medicina, no Programa de Pós-Graduação em Psicologia Social e Institucional da UFRGS e é Professor Médico-Assistente do Hospital de Clínicas de Porto Alegre, no Serviço de Medicina Ocupacional/Ambulatório de Doenças do Trabalho e na Residência em Medicina do Trabalho. Publicou 48 artigos em periódicos especializados, 50 capítulos de livros e 9 livros. Orientou 29 dissertações de mestrado e 4 de doutorado. Atualmente, orienta 3 estudantes de doutorado e 2 de mestrado. Atua na área de Psicologia, com ênfase em Psicodinâmica e Clínica do Trabalho e na área da Medicina, com ênfase em Medicina do Trabalho. Líder do Grupo de Pesquisa Laboratório de Psicodinâmica do Trabalho da UFRGS. E-mail: merlo@ufrgs.br

Endereço: Programa de Pós-Graduação em Psicologia Social e Institucional (PPGPSI) - Rua Ramiro Barcelos, 2.777 - Sala 212 - 2 Andar - Cep: 90035-003

\section{Perla Alves Martins Lima}


Mestra em Psicologia pela Universidade Federal do Amazonas, Servidora do Tribunal de Justiça de Roraima e Professora da Universidade Estadual de Roraima.

E-mail: perla.psicologia@gmail.com

Endereço: Universidade Estadual de Roraima. Rua 7 de Setembro, 231, Canarinho. Boa Vista/RR. CEP: 69306-530

\section{Ana Magnólia Mendes}

Professora na Universidade de Brasília - UnB. Instituto de Psicologia, Programa de Pós Graduação em Psicologia Social, do Trabalho e das Organizações. Estágio Sênior no Freudian-Lacanian Institute Après-Coup Psychoanalytic Association em parceria com a School of Visual Arts, New York (EUA). Estágio pós-doutorado no Conservatoire National des Arts et Métiers (CNAM), Paris, doutorado em Psicologia pela UnB e sanduíche na Universidade de Bath, Inglaterra.

E-mail: anamag@unb.br

Endereço: Instituto de Psicologia • Universidade de Brasília • Campus Universitário Darcy Ribeiro, Instituto Central de Ciências Sul, prédio Minhocão, Brasília, DF CEP: 70 910-900 